\title{
ESTIMATION OF VOLTAGES AND CURRENTS DUE TO LIGHTNING STROKES TO TRANSMISSION LINES
}

\author{
Klshore N.K and Nagabhushana G.R.
Student Member \\ Department of High Voltage Engineering \\ Indian Institute of Science \\ Bangalore 560012
}

\section{Abstract}

This paper presents an improved equivalent circuit representation for the lightning stroke to estimate the magnitudes and waveshapes of currents and voltages through transmission system components due to lightning strokes. Results indicate that arrester currents can go as high as $130 \mathrm{kA}$ with a front time of the order of 15us, while the arrester potentials are substantially rectangular lasting anywhere upto 60 us. Transformer potentials are initially oscillatory exceeding the BIL. This could be dangerous. Thus, this work was successful in improving the equivalent circuit representation of the lightning stroke and highlighted interesting areas for further research.

\section{1) Int roduction}

Modern life in all aspects is dependant on Electric Power, requiring continuity of power supply even under highly adverse circumstances. Several studies by IEE, IEEE \& CIGRE in UK, USA, Canada and Europe have identified lightning to be the single largest cause of outages on EHV systems contributing to nearly $50 \%$ of the outages $[1,2,3]$.

It is quite clear from a study of the literature that there has been only limited efforts towards analytically estimating the voltages and currents through transmission system components due to Lightning strokes $\{4-10\}$. Such studies, invariably represent thundercloud as a charged capacitor [9] and stroke channel as a lossless transmission line or an inductance. The object struck is sometimes represented as a lumped resistance $[4,7,9,10]$ and sometimes as a short transmission line $[5,6,8,9]$. Tower footing is represented by a lumped fixed resistor. Thus, it is believed that there is considerable scope for improving the representation, to estimate the voltages and currents
Presentiy the current source model due to Diesendorf [10] is very extensively used to estimate the lightning performance of transmission systems. This model has the merit of being simple and yields highly acceptable results, though it requires an assumption of the magnitude and waveshape of source current.

Perhaps, for the first time Little [11] represented the stroke channel as a lossy transmission line. Here, a constant lumped resistance is used to represent the loss compnoent. A ladder LCR network is used to represent the stroke channel, which is terminated in a fixed resistance representing the ground resistance.

Dutta and Nagabnushana 【12】 were perhaps the first to consider the nonlinearity of the stroke channel resi- ance. Kishore and Nagabhushana [13-18], later improved this representation using the experimentally determined formulation for the resistance behaviour of impulse arcs $[13,16,18]$.

Recently, Mattos and Christopolous [19] proposed a model similar to that proposed by Little [11] by including nonlinear arc resistance behaviour based on Braginskii's formulation [20].

This paper presents the computed results using the improved representation for the stroke to phase conductor.

\section{2) Equivalent Circuit Representatic}

The improved representation
the equivalent circuit of t
lightning stroke is discussed
detail in earlier papers [13-15, 17 -
$18]$
A capacitor charged to clc:
potential represents the thunde
cloud. A lossy transmission li-s
represents the stroke channel, The
lossy nature is incorporated by
lumping the total arc resistance $R$ as
$R / 4$ at the begining \& end of the
$s$ and as $R / 2$ at the middle of the
line, and




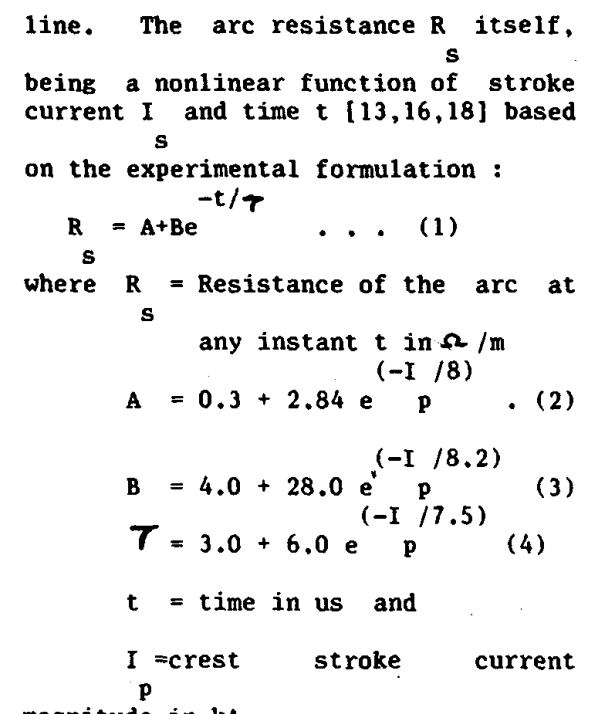

magnitude in $\mathrm{kA}$.

Fig 1 shows the equivalent circuit diagram. Target object considered is Phase conductor and is represented by it's surge impedance and travel time. Gapless metal oxide arresters have been considered and they are represented as a lumped nonlinear resistance whose voltage-current characteristics are expressed by a three-slope relationship, each slope of the form

$$
\mathbf{v}=\mathbf{k i}
$$
where $v=$ instantaneous arrester potential in $\mathrm{kV}$ $i$ = instantaneous arrester current in $A$

k \& B are constants (different for the three slopes) based on the manufacturer's data sheets.

A power transformer, when unloaded is represented by its stray capacitance and when on load by the leakage reactance in parallel with the stray capacitance.

Utilizing the above representation strokes to phase conductors were computed using Domme1's method [21].

\section{3) Results and Discussions :}

This study focuses on the influence of surge arresters and transformers (located in the station) on the magnitude and waveshapes of voltages and currents. Mostly, lines terminate in power transformers (in a station), which would mostly be in a loaded condition but could, on rare occasions, be in unloaded condition also. Therefore, both cases have been studied. Though EHV transformers are almost always protected by surge arresters, computations have also been made for lines terminated in arresters only. There are two further of cases interest :

1) Strokes to the line significantly away from the station - distant strokes

2) Strokes to the line very close to the station - closeby strokes

In the former, the arrester current is somewhat limited by the line surge impedance whereas in the latter, there is little influence of the line impedance. The above two cases have been studied by considering

1) Strokes occcuring $12 \mathrm{~km}$ away from the station to simulate distant strokes and

2) Strokes just $30 \mathrm{~m}$ away from the arresters to simulate closeby strokes.

In all these studies, lines are assumed to extend to infinity from the point of strike away from the station.

With these considerations the computations have been made for a 400 kV system on a single phase basis, neglecting the interphase couplings. As a result the computed voltages are conservative.

Fig 2 shows the computed results for a distant stroke to a phase conductor terminated in a surge arrester only for the case of cloud potential $\mathrm{V}=100 \mathrm{MV}$ and cloud capacitance $C^{C}=0.2$ uF . The figure $c$

shows the behaviour of line voltage $V$ at the point of strike, arrester current $I$ and arrester potential $V$ SA as a function of time. $v$ reaches $a$ peak value of $18.2 \mathrm{MV}$ in $15^{\mathrm{L}}$ us. I peak value of $18.2 \mathrm{MV}$ in 15 us. $\mathrm{I}$ reaches a peak value of $96 \mathrm{kA}$ in 15 us. $v$ is substantially rectangular SA

with a maximum value of $1.02 \mathrm{MV}$. This value of $V$ at these current levels SA

is considered realistic based on the manufacturer's catalogues.

The results for an identical case for a stroke closeby to the station (surge arrester) are shown in Fig. 3. In this case $I$ is oscillatory with a SA

first peak of $130 \mathrm{kA}$ at 15 us, falling to $50 \%$ value in 30 us. $v$ is substantially rectangular at about 1. MV. $V$ reaches a peak of $1.8 \mathrm{MV}$ in 8 L.

us and remains substantially constant around $1.1 \mathrm{MV}$. However, there are 
occasional 6scillations lasting for a microsecond with a peak to peak excursion of $3 \mathrm{MV}$.

In the event of a direct stroke to a phase conductor, there is a high probability of flashover of the line insulation and is of considerable practical significance. Therefore this aspect has also been considered . Line flashover characteristics are based on the curves due to Anderson

[22]. For the case of $\mathrm{V}=100 \mathrm{MV}$ and $c=0.2 \mathrm{uF}$ the results considering line flashover are shown in fig 4. Here, I reaches a peak value of 98

$\mathrm{kA}$ in about 14 us and is oscillatory in nature. $v$ is flat with a maximum SA

value of $1.1 \mathrm{MV}$. The line voltage at the point of strike reaches a peak value of $3.9 \mathrm{MV}$ in about 1 us and the insulator string at the tower flashes at about $2.3 \mathrm{MV}$ in about $5.4 \mathrm{us.}$ Subsequent to flashover, the voltage (at the location of flashover) does not go down to zero as may perhaps be expected but reduces to about $25 \%$ of initial voltage.

Results for the case of $V=100$ $c$

MV and $\mathrm{C}=0.2 \mathrm{uF}$ for a stroke to phase conductor terminated in an unloaded transformer are shown in Fig 5. The distance between the arrester and transformer is $3 \mathrm{~m}$. The waveshapes of the line voltge $v$. arrester

current I and arrester potential $\mathrm{V}$ SA

are same as shown in fig 2 for the case of lines terminated in surge arresters only. The transformer voltage $v$ is initially oscillatory

settling down to arrester voltage in about 4 us. The initial oscillations are in the range of $0.4 \mathrm{MV}$ to $1.6 \mathrm{MV}$ lasting for 4 us with a period of 0.5 us. Thus initial oscillation exceeds the BIL- 1.05 to 1.42 MV. On increasing the separation distance the period and duration of initial oscillation increase without any change in the range of peak values.

The results for an identical condition considering a loaded transformer show that waveshapes and magnitudes are very close to the unloaded case.

Thus it is seen that arrester currents can go as high as $130 \mathrm{kA}$ with a front time of 15 us. It may be mentioned that the high current impulse tests on surge arresters specify a waveshapes of $4 \times 10$ us. $[23,24,25]$. The arrester potentials are substantially rectangular for durations upto 60-80 us, whereas standard lightning impulse voltages have $1.2 / 50$ us $[23,24]$. Behaviour of transformer insulation to such rectangular pulses is not known and it would be interesting to study this aspect . Transformer potentials are initially oscillatory exceeding BIL. This could be dangerous. Occurance of such oscillations in the field needs to be verified.

\section{4) Conclusion:}

a) This work has been successful in improving the equivalent circuit representation of the lightning stroke

b) Computed arrester currents and potentials are significantly different from those prescribed in the current international standards. In view of this, it may be necessary to have a relook at some parameters used in high voltage testing.

c) There is little field data on arrester currents to make meaning ful comparison. Hence it would be useful to obtain such field data.

d) Transformer potentials could be initially oscillatory, the levels exceeding the BIL. This is dangerous. The occurance of these oscillations in the field needs to be verified and appropriately recognised.

\section{References}

[1] CIGRE Working Group 33-02, Internal Voltages, Evaluation of questionaires on characterizing data of system with highest voltages $>=300 \mathrm{kV}$, Document 3378 (WG -02) (part a to e) IWD (1978).

[2] Report of joint IEEE-EEI subject committee on EHV line voltages, IEEE Trans. on PAS, Vol.86, p.547 (1967).

[3] Connor, R.A.W and Parkins, R.A., 'Operations statistics in the management of large distribution systems', Proc. IEE, Vol.113, p.1823 (1966).

[4] Fortescue, C.L. and Conwe11, R.N. 'Lightning discharge and line protective measures', Trans.AIEE, Vol.150, Pt III pp.1090-1100 (1931)

[5] Jordan, C.A., 'Lightning computation for transmission lines with overhead ground wires', Part I, II, III', General Electric Review, Vol.37,pp.130-137,243-250 (1934).

[6] Bewley, L.v., 'Protection of transmission lines against lightning: Theroy and calculations ibid, Vo1.40, pp.180-188, (1937). 
[7] Koncel, E.F., 'Potential of a transmission line tower top when struck by lightning', Trans. AIEE, Vol.75, Pt.III, pp.457-462, (1956).

[8] Miller, c.J., 'Anomalous flashovers on transmission lines,' ibid, pp.897-902 (1956).

[9] Griscom, S.C., Skooglund, J.W. and Hileman, A.R., 'The influence of the prestrike on transmission line lightning performance', ibid, Vo1.77, Pt III, pp.933-941 (1958).

[10] Diesendorf, W., .'Insulation Coordination in High Voltage Electric Power Systems' (book), But terworths (London), (1978).

[11] Little, P.F., 'Transmission line representation of lightning return stroke', J.Phys.D., Vo1.11 pp.1892-1910 (1978).

[12] Sanjib Dutta and Nagabhushana G.R 'Estimation of tower top potentials and tower currents due to a lightning return stroke' Proc. of Conf. \& workshop on EHV Technology, Bangalore, pp. 23-27 (1984).

[13] Kishore N.K, and Nagabhushana G.R 'Digital simulation of lightning strokes', Proc. of Vth ISH Braunschweigh FRG, paper 83.09, (1987).

[14] Kishore N.K, and Nagabhushana G.R 'Digital computation of lightning currents', Proc. II Workshop \& Conf. on EHV Technology . Bangalore, (1989).

[15] Kishore N.K, Rajeswari Devi S, and Nagabhushana G.R. 'Ground Potentials and Currents due to Lighting Stroke', Proc. II Int1. Conf. \& Workshop on EM Interference and Compatibility, Bangalore (1989).

[16] Kishore N.K, and Nagabhushana G.R 'Behaviour of Lightning Impulse Arcs', Proc. of Workshop cum Symp. on Beams \& Plasmas : Applications to Materials Tech. Bombay, India (1990).

[17] Kishore N.K, and Nasabhushana G.R 'Digital Computation of currents and voltages due to lightning strokes to Power system components, Proc. VI MPSC, Bombay India (1990).
[18] Kishore N.K, 'Digital computation of magnitudes and waveshapes of voltages and currents on transmission system components due to Lightning strokes'

- Thesis submitted for PhD degree of Indian Institute of Science, Bangalore, India. (1990).

[19] Mattos, M.A. daF and Christopolous.C., 'A nonlinear transmission line model of the lightning return stroke', IEEE Trans. on EMC, Vol.30 No.3 pp. 401 - 406 (1988).

[20] Braginskii,S.I., 'Theroy of the development of a spark channel Sov. Phys. JETP, Vol.35 (7) No. 7. pp. 1068-74 (1958).

[21] Domme1,H.W., 'Digital computer solution of electromagnetic transients in single and mult tiphase networks', Trans. IEEE PAS, Vo1 88, No.4,pp.388396 (1969).

[22] Anderson, J.G, 'Transmission line reference book-345 kV and above'. II Edition, Chapter 12, EPRI Palo Alto, California (1982).

[23] IEC :' High Voltage Test Techniques ', IEC publication 60 (1973).

[24] IEEE Standard Techniques for High Voltage Testing (1978).

[25] IEEE Standard for Surge Arresters for AC Power Circuits, IEEE New York (1984).

\section{ACKHOLLEDGEYERTS}

The authors wish to thank the authorities of the Indian Institute of Science, Bangalore for the encouragement in this work and permission to present this paper.

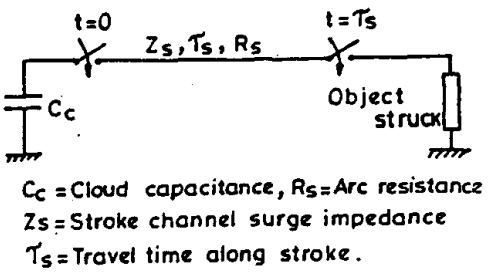

Fis 1 : Equivalent circuit for a Lightning stroke. 

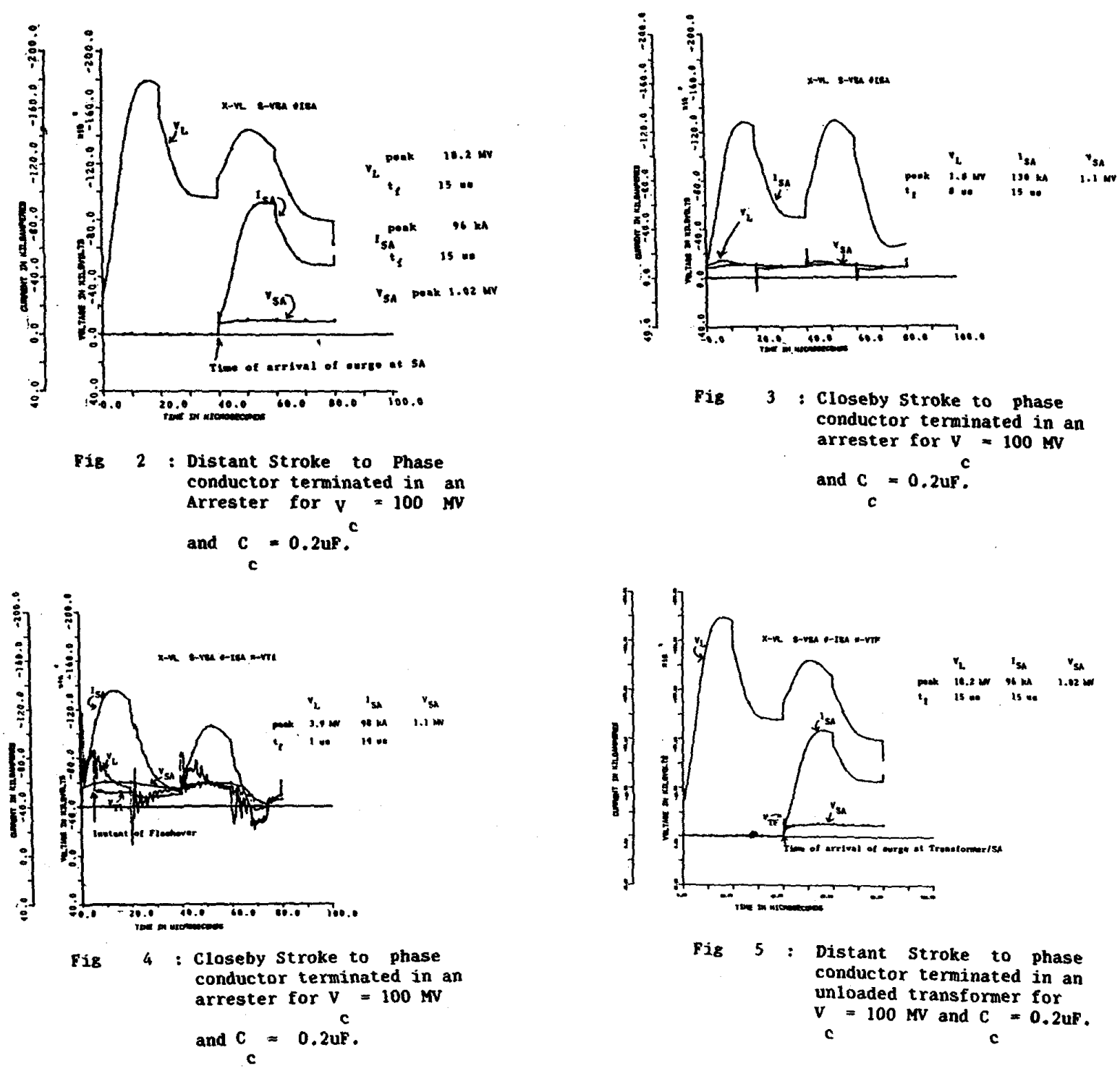

Considering insulation

flashover. 